\title{
Screening Level of PAHs in Sediment Core from Lake Hongfeng, Southwest China
}

\author{
Jian-Yang Guo $\cdot$ Feng-Chang Wu $\cdot$ Liang Zhang $\cdot$ \\ Hai-Qing Liao $\cdot$ Run-Yu Zhang $\cdot$ Wei Li $\cdot$ \\ Xiao-Li Zhao $\cdot$ She-Jun Chen $\cdot$ Bi-Xian Mai
}

Received: 21 December 2009/Accepted: 21 June 2010/Published online: 10 July 2010

(C) The Author(s) 2010. This article is published with open access at Springerlink.com

\begin{abstract}
Using data from a 25-year retrospective of polycyclic aromatic hydrocarbons (PAHs) in sediment core from Lake Hongfeng, Southwest China, their possible sources and potential toxicologic significance were investigated. The total PAH concentrations (16 priority PAHs as proposed by the United States Environmental Protection Agency) in sediments ranged from 2936.1 to $5282.3 \mathrm{ng} / \mathrm{g}$ and gradually increased from the analyzed deeper sediments to surface sediments. PAHs were dominated by low molecular-weight components, especially phenanthrene (PHEN) and fluorene (FLU). However, a significantly increased number of high molecular-weight (HMW) PAHs was found in upper segments. The temporal trends of individual PAH species suggest that there may have been a change in energy use from low- to high-temperature combustion, especially after approximately 2001. PAH input to Lake Hongfeng originated mainly from domestic
\end{abstract}

Electronic supplementary material The online version of this article (doi:10.1007/s00244-010-9568-4) contains supplementary material, which is available to authorized users.

J.-Y. Guo · F.-C. Wu ( $\varangle)$ - L. Zhang · R.-Y. Zhang · W. Li State Key Laboratory of Environmental Geochemistry, Institute of Geochemistry, Chinese Academy of Sciences, Guiyang 550002, China

e-mail: wufengchang@vip.skleg.cn

F.-C. Wu · L. Zhang · H.-Q. Liao · X.-L. Zhao

State Environmental Protection Key Laboratory for Lake

Pollution Control, Research Center of Lake Eco-Environment, Chinese Research Academy of Environmental Sciences, Beijing 100012, China

S.-J. Chen · B.-X. Mai

State Key Laboratory of Organic Geochemistry,

Guangzhou Institute of Geochemistry,

Chinese Academy of Sciences, Guangzhou 510640, China coal combustion and biomass burning, whereas fuel combustion characteristics have also been found in recent years. Sediment-quality assessment implied that potential adverse biologic impact could be a probability for most low-ring PAHs (including naphthalene, acenaphthylene, acenaphthylene, FLU, PHEN, and anthracene). Nevertheless, more concern should be paid to HMW PAHs in the future due to their rapidly increasing trends in upper sediments. Because only one core was analyzed in this study, more work is needed to confirm the sources and toxicity of PAHs in Lake Hongfeng.

Polycyclic aromatic hydrocarbons (PAHs) are ubiquitous in various environmental compartments. They can be released into the environment by way of various anthropogenic and natural processes. Potential source candidates include incomplete combustion of fossil fuels, burning of biomass or municipal wastes, accidental oil spillage, and digenesis of organic matter (Liu et al. 2005; Guo et al. 2006, 2007). Due to their high hydrophobicity and strong particulate-oriented behaviors, PAHs are partitioned preferentially to sediments in aquatic ecosystems (Kannan et al. 2005; Colombo et al. 2006). Therefore, sediment is the most important sink for PAHs in the aquatic environment. Because of their potential (or, in some cases, proven) carcinogenicity, immunotoxicity, genotoxicity, and reproductive toxicity, PAHs in contaminated sediments can directly affect sediment-dwelling organisms (Sverdrup et al. 2002; Gu et al. 2003). Moreover, contaminants in sediment can re-enter the aquatic environment by way of resuspension, resulting in secondary contamination (Zeng and Venkatesan 1999). Thus, contaminated sediments represent a continuing source of toxic substances in aquatic environments that could be harmful to wildlife and humans 


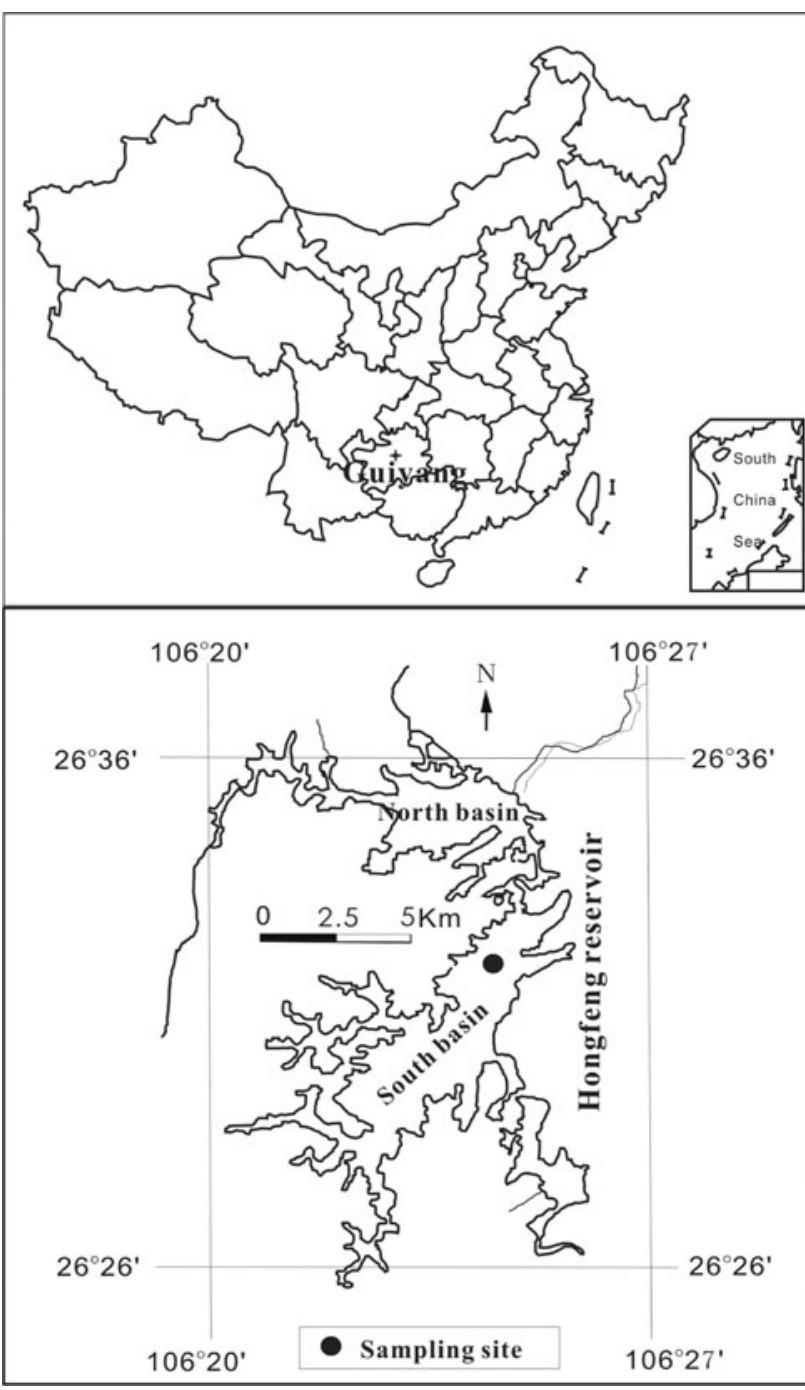

Fig. 1 Map of the sampling sites

by way of the food chain (Kannan et al. 2005). Therefore, both the potential toxicology and the fate of PAHs in sediments have provoked considerable concern.

Lake Hongfeng $\left(106^{\circ} 20^{\prime} \mathrm{E}\right.$ to approximately $106^{\circ} 27^{\prime} \mathrm{E}$ and $26^{\circ} 26^{\prime} \mathrm{N}$ to approximately $26^{\circ} 36^{\prime} \mathrm{N}$ ) is a reservoir, established in 1960, that lies $33 \mathrm{~km}^{2}$ west to Guiyang City, the capital city of Guizhou Province in Southwest China (Fig. 1). It has surface and catchment areas of 57.2 and $1596 \mathrm{~km}^{2}$, respectively, with an average depth of $10.5 \mathrm{~m}$ and a volume of $6.01 \times 10^{8} \mathrm{~m}^{3}$ (Li et al. 2008). It is the most important drinking-water source for Guiyang City. There are nearly two dozen factories (including a firepower plant and several chemical plants, etc.) in its catchment area, and a large volume of improperly treated wastewater has been discharged to this reservoir (He et al. 2008). These factors, together with contaminants discharged by a great number of yachts that are shuttled across the lake, have caused water quality to greatly deteriorate and thus seriously threaten the drinking-water supply. To keep up with the rapid urbanization and industrialization in the catchment area and to provide more quality water, the local government has undertaken great efforts to improve drinking-water sources (http://www.law-lib.com). The degrees of eutrophication and mercury pollution have been reported elsewhere ( $\mathrm{He}$ et al. 2008), but no part of that report investigated persistent organic pollutants.

The main objectives of the present work were (1) to determine the temporal trend of PAH contamination in Lake Hongfeng, (2) to identify possible sources of contamination, and (3) to assess potential toxicologic impacts.

\section{Materials and Methods}

Chemicals and Reagents

A standard solution of 16 United States Environmental Protection Agency (USEPA) priority PAHs (including naphthalene [NAP], acenaphthylene [ACE], acenaphthene $[\mathrm{AC}]$, fluorene $[\mathrm{FLU}]$, phenanthrene [PHEN], anthracene [ANT], fluoranthene [FLUO], pyrene [PYR], benzo [a]anthracene $[\mathrm{B} a \mathrm{~A}]$, chyrsene $[\mathrm{CHR}]$, benzo $[\mathrm{b}]$ fluoranthe $[\mathrm{B} b \mathrm{~F}]$, benzo [k]fluoranthene $[\mathrm{B} k \mathrm{~F}]$, benz [a]pyrene $[\mathrm{B} a \mathrm{P}]$, indeno [1,2,3-cd]pyrene [INP], dibenz [ah]anthrance [DBA], and benzo [ghi]perylene [BghiP]) and internal standards (2-fluorobiphenyl and terphenyl- $d_{14}$ ) were purchased from Accustandards (New Haven, CT). A mixture solution of 5 perdeuterated PAHs (naphthalene- $d_{8}$, acenaphthene- $d_{10}$, phenanthrene- $d_{10}$, chrysene- $d_{12}$, and perylene $d_{12}$ ) were obtained from Ultra Scientific (North Kingstown, RI). All solvents and reagents used in the extraction and cleanup procedures were analytic-reagent grade, and all organic solvents were redistilled. Neutral silica gel (100-200 mesh) and alumina (80-100 mesh) were extracted with a mixture of dichloromethane and methanol $(1: 1)$ for $72 \mathrm{~h}$ and baked at $180^{\circ} \mathrm{C}$ and $250^{\circ} \mathrm{C}$, respectively, for $12 \mathrm{~h}$. Sodium sulfate was baked at $450^{\circ} \mathrm{C}$ and stored in sealed containers.

\section{Sampling}

Sediment core was taken from the center of Lake Hongfeng in May 2006 (Fig. 1). A 37 cm-long sediment core, mainly composed of silt with a little gravel in the deeper segments, was collected by a gravity corer and sectioned in situ at $1-\mathrm{cm}$ intervals. The cored sediments were undisturbed, as indicated by clear water, sediment interface, and preservation of fine-sediment laminations, and therefore had little influence on radiodating and chemistry results. The sediments were wrapped in baked $\left(450^{\circ} \mathrm{C}\right)$ aluminum foil and 
transported on ice to the laboratory, where they were stored at $-20^{\circ} \mathrm{C}$ until further treatment.

\section{Extraction and Instrumental Analyses}

The sample extraction procedures have been described in detail elsewhere (Mai et al. 2002). In brief, an aliquot of approximately $5 \mathrm{~g}$ freeze-dried sample, spiked with a mixture of five perdeuterated PAHs as recovery surrogates and $2 \mathrm{~g}$ activated copper added for desulfurization, was Soxhlet-extracted with $200 \mathrm{ml}$ mixture hexane and acetone $(1: 1, \mathrm{v}: \mathrm{v})$ for $48 \mathrm{~h}$. The extracts were concentrated and solvent-exchanged to hexane. Cleanup and fractionation of the concentrated extract was performed using an alumina/ silica gel chromatographic technique. The aliphatic and aromatic fractions were successively eluted with $15 \mathrm{ml}$ hexane and $70 \mathrm{ml}$ dichloromethane/hexane (3:7 v:v), respectively. The second fraction was concentrated under a gentle flow of high-purity nitrogen to $200 \mu \mathrm{l}$. The internal standards 2-fluorobiphenyl and terphenyl- $\mathrm{d}_{14}$ were added before instrumental analysis.

Analyses of PAHs were performed on an Agilent 6890 gas chromatograph (GC) system equipped with an Agilent 5975B mass selective detector operating in selective ion monitoring mode using a DB-5 capillary column (60 m length $\times$ $0.25 \mathrm{~mm}$ i.d. $\times 0.25 \mu \mathrm{m}$ film thickness). Splitless injection of $1.0 \mu \mathrm{l}$ sample was conducted with an auto-sampler. The GC oven temperatures were programmed from $90^{\circ} \mathrm{C}$ to $180^{\circ} \mathrm{C}$ at a rate of $10^{\circ} \mathrm{C} / \mathrm{min}$, to $220^{\circ} \mathrm{C}$ at a rate of $2^{\circ} \mathrm{C} / \mathrm{min}$, and then to $290^{\circ} \mathrm{C}$ at a rate of $8^{\circ} \mathrm{C} / \mathrm{min}$ (hold for $30 \mathrm{~min}$ ).

\section{Dating of the Sediment Core}

Dating of sediment core was performed using ${ }^{137} \mathrm{Cs}$ activity. The method for the determination of ${ }^{137} \mathrm{Cs}$ activity has been described elsewhere (Wan et al. 2005). In brief, ${ }^{137} \mathrm{Cs}$ activity was determined using gamma-spectrometry on a Canberra S-100 multichannel spectrometer mated to a GCW3022 H-P Ge coaxial detector (efficiency 50\%). The gamma peak at $661.6 \mathrm{keV}$ peak of ${ }^{137} \mathrm{Cs}$ was used to determine the ${ }^{137} \mathrm{Cs}$ activity of these standards. Liquid standards were supplied by the Institute of Atomic Energy, Chinese Academy of Sciences (catalog no. 7137 and source no. 586-26-2). Based on the pronounced peak at the 33- to 34-cm interval (Supplemental Fig. 1), an average sedimentation rate of $0.81 \mathrm{~cm} \mathrm{y}^{-1}$ was obtained.

\section{Quality Control and Quality Assurance}

The surrogate recoveries in all samples were $56.2 \% \pm$ $8.8 \%$ for naphthalene- $d_{8}, 73.0 \% \pm 10.9 \%$ for acenaphthene- $d_{10}, 69.8 \% \pm 17.8 \%$ for phenanthrene- $d_{10}, 89.1 \% \pm$ $7.4 \%$ for chrysene- $d_{12}$, and $95.9 \% \pm 15.9 \%$ for perylene- $d_{12}$.
A procedural blank, triplicate spiked blank, and triplicate spiked matrices were analyzed for each batch of samples. The mean recoveries of 16 PAHs ranged from $75.8 \% \pm$ $4.9 \%$ to $114.3 \% \pm 8.2 \%$ in triplicate spiked blanks and from $60.8 \% \pm 1.1 \%$ to $120.9 \% \pm 9.1 \%$ in triplicate spiked matrices. Only trace levels of targets were detected in blanks and were subtracted from those in sediments samples. Detection limits were $0.03-0.05 \mathrm{ng} / \mathrm{g}$ dry weight for PAHs (defined as a signal-to-noise ratio $[\mathrm{S} / \mathrm{N}]>10$ ). The results were expressed on a dry-weight basis, and surrogate recoveries corrected.

\section{Results and Discussion}

Temporal Trends of PAHs in the Sediment Core

PAHs were analyzed only in the upper portion of the sediment core $(0$ to $20 \mathrm{~cm}$ ). The temporal trend of 16 USEPA-proposed priority PAHs (designated as $\Sigma \mathrm{PAH}_{16}$ ), as assessed against depth and depositional year, are showed in Fig. 2. $\Sigma \mathrm{PAH}_{16}$ concentrations in sediments ranged from 2936.1 to $5282.3 \mathrm{ng} / \mathrm{g}$ (all concentrations are normalized to dry weights except where specified), and the fluxes ranged from 985.2 to $1772.4 \mathrm{ng} \mathrm{m}^{-2} \mathrm{y}^{-1}$. The flux was calculated using the following equation (Eq. 1):

$\mathrm{F}=C i \rho i \gamma i$,

where $\mathrm{C}_{\mathrm{i}}(\mathrm{ng} / \mathrm{g}), \rho_{\mathrm{i}}\left(\mathrm{g} / \mathrm{cm}^{3}\right)$, and $\gamma_{\mathrm{i}}(\mathrm{cm} / \mathrm{y})$ refer to the concentration, the dry mass density, and the sedimentary

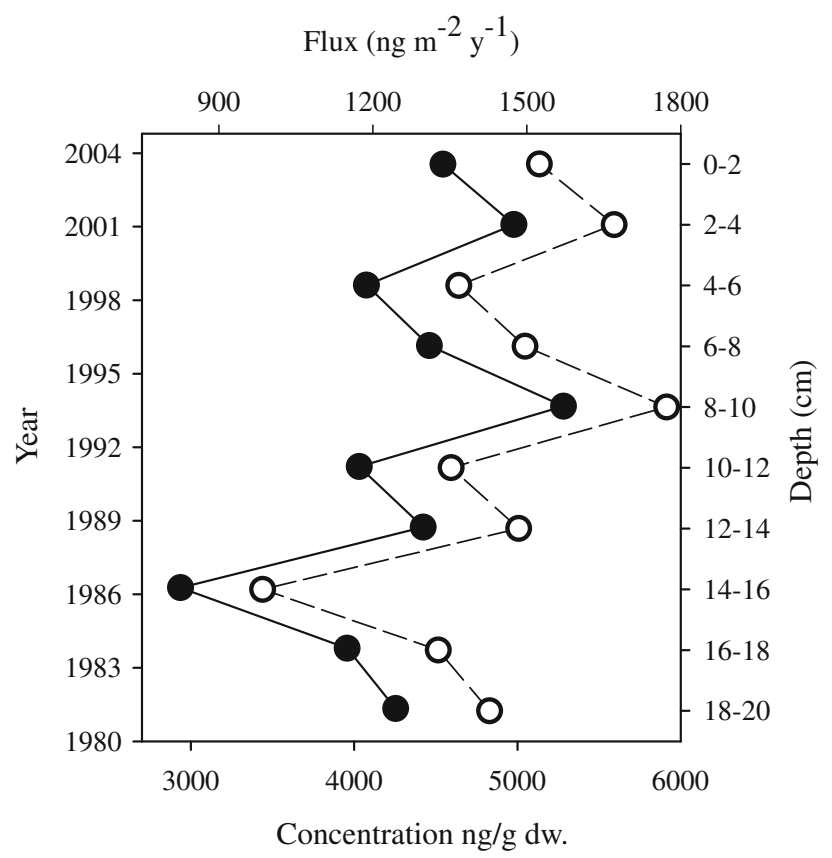

Fig. 2 Vertical profile of PAHs assessed against depositional year and depth. Solid circles $=$ concentrations; open circles $=$ fluxes 
rate of the segment $\mathrm{i}$, respectively. Generally, the $\mathrm{\Sigma PAH}_{16}$ concentrations gradually increased from the analyzed deeper segments to surface sediments. Among the 16 USEPA-priority PAHs, PHEN was the predominant PAH, followed by NAP and ANT, accounting for $35.7 \% \pm 7.0 \%$, $16.2 \% \pm 4.3 \%$, and $13.9 \% \pm 2.6 \%$ of total PAHs, respectively (Supplemental Fig. 2). PHEN and FLU mainly originated from low- and moderate-temperature combustion processes, such as biomass and domestic coal burning (Harrison et al. 1996; Mai et al. 2003). The predominance of PHEN and ANT in the sediments suggests that PAHs in sediments were mainly from biomass and domestic coal burning. On the contrary, high molecular-weight (HMW) PAHs (including $\mathrm{B} b \mathrm{~F}, \mathrm{~B} k \mathrm{~F}, \mathrm{~B} a \mathrm{P}, \mathrm{DBA}, \mathrm{INP}$, and BghiP) accounted for only $11.5 \% \pm 4.5 \%$ of total PAHs. Nevertheless, the contribution of HMW PAHs to total PAHs significantly increased (an increase from $10.1 \%$ to $23.6 \%$ ) from the 4- to $6-\mathrm{cm}$ sediment layer to the top sediment layer. The opposite (a decrease from $75.9 \%$ to $55.7 \%$ ) was true for low molecular-weight (LMW) PAHs, including NAP, AC, ACE, FLU, PHEN, and ANT.

The vertical profiles of 16 PAHs in sediment core are shown schematically in Fig. 3. The temporal trends of PHEN and FLU basically followed that of total PAHs before 1995 but was different thereafter, especially in surficial sediment, where the concentrations of PHEN and FLU decreased significantly. This suggests that there may have been a change in energy use from low- to high-temperature combustion, especially after approximately 2001. B $a \mathrm{~A}$ and CHR are dominant in the emissions produced by petroleum combustion (Sicre et al. 1987). The temporal trends of $\mathrm{B} a \mathrm{~A}$ and CHR in the sediment core were roughly similar. Different from those of PHEN and FLU, the concentrations and fluxes of CHR gradually increased from deep to surface sediments, with a rapid increase after approximately 1998 . This provided more source evidence for $\mathrm{B} a \mathrm{~A}$, indicating that more liquid fossil fuel may have been used in the past decade. HMW PAHs are products of high-temperature combustion processes, mostly involving industrial coal combustion, vehicular emission, and gas-fired cooking (Miguel and Pereira 1989; Harrison et al. 1996; Mai et al. 2003). The temporal trends of HMW PAHs were quite similar to each other and resembled that of $\mathrm{B} a \mathrm{~A}$, which was characterized by a rapid increase after approximately 1998 . This confirms that there was probably was a change in energy use from low- to high-temperature combustion after approximately 1998.

\section{Source Identification}

Source identification is important for developing control strategies for environment pollution. A frequently adopted method for PAH source identification is using the diagnostic ratios of PAH (typically isomers). This method is based on the hypothesis that paired chemicals are diluted to a similar extent and that the ratios remain constant en route from sources to receptors (Katsoyiannis et al. 2007). The common ratios used include ANT/ANT + PHEN, BaA/ $\mathrm{B} a \mathrm{~A}+\mathrm{CHR}, \quad$ FLUO/FLUO + PYR, INP/INP + BghiP, and $\mathrm{B} a \mathrm{P} / \mathrm{BghiP}$ (Liu et al. 2005; Brändli et al. 2007; Peng et al. 2008). Values of INP/INP + BghiP $<0.2$ and FLU/ FLU + PYR $<0.4$ usually imply a petrogenic source, whereas values for both ratios $>0.5$ suggest a combustion source of coal and biomass. If the FLU/FLU + PYR ratio is between 0.4 and 0.5 and the INP/INP + BghiP ratio is between 0.2 and 0.5 , a liquid fossil fuel combustion origin is suggested (Guo et al. 2006). The characteristic PAH diagnostic ratios in the sediment core from Lake Hongfeng are listed in Table 1. ANT/ANT + PHEN and $\mathrm{B} a \mathrm{~A} /$ $\mathrm{B} a \mathrm{~A}+\mathrm{CHR}$ in the sediment core were $0.12 \pm 0.02$ (range $0.11-0.16$ ) and $0.40 \pm 0.03$ (range 0.38-0.48), respectively. They both strongly suggest a pyrogenic source. Together with the ratios of FLUO/FLUO + PYR and INP/ INP + BghiP, with values of $0.52 \pm 0.02$ (range 0.490.55 ) and $0.53 \pm 0.06$ (range $0.47-0.64$ ), respectively, it can be concluded that PAH input to Lake Hongfeng mainly originated from domestic coal combustion and biomass burning. Some fuel-combustion characteristics were also found in the upper sediments. For example, as traces of vehicular emission (Miguel and Pereira 1989; Harrison et al. 1996), INP and BghiP concentrations in sediments significantly increased in upper sediments $(0-6 \mathrm{~cm})$, and INP/INP + BghiP ratios were between 0.47 and 0.50 (mean 0.49) and thus represented some evidence of fuel combustion in recent years.

\section{Potential Toxicologic Significance}

\section{Assessing Sediment Quality Using Biologic Thresholds}

One method for assessing potential toxicologic impacts is to use biologic thresholds. The effects-range low (ERL) and the effects-range median (ERM) values formulated by Long et al. (1995) have been widely used for assessing sediment quality (McCready et al. 2000; Qiao et al. 2006; $\mathrm{Xu}$ et al. 2007). ERL and ERM values are intended to define chemical concentration ranges that are rarely, occasionally, or frequently associated with adverse biologic effects. In the present work, the measured concentrations of PAHs in surficial sediment was used for comparison with ERL and ERM values to derive hazard ratios (HR_ERL and HR_ERM) representing the ratio of measured concentration of individual PAHs species to ERL and ERM values, respectively. If HR_ERL was $<1$, adverse biologic effects were rarely associated with the PAH contamination. If HR_ERL was $>1$ or HR_ERM was $>1$, adverse biologic effects were occasionally or 
Fig. 3 Vertical profiles of 16 PAHs assessed against depositional year and depth. Solid circles $=$ concentrations; open circles $=$ fluxes
Flux (ng m-2 $\left.\mathrm{y}^{-1}\right)$

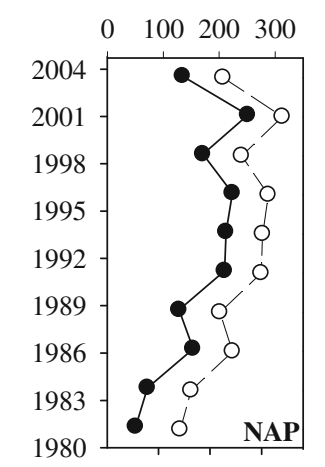

2505007501000

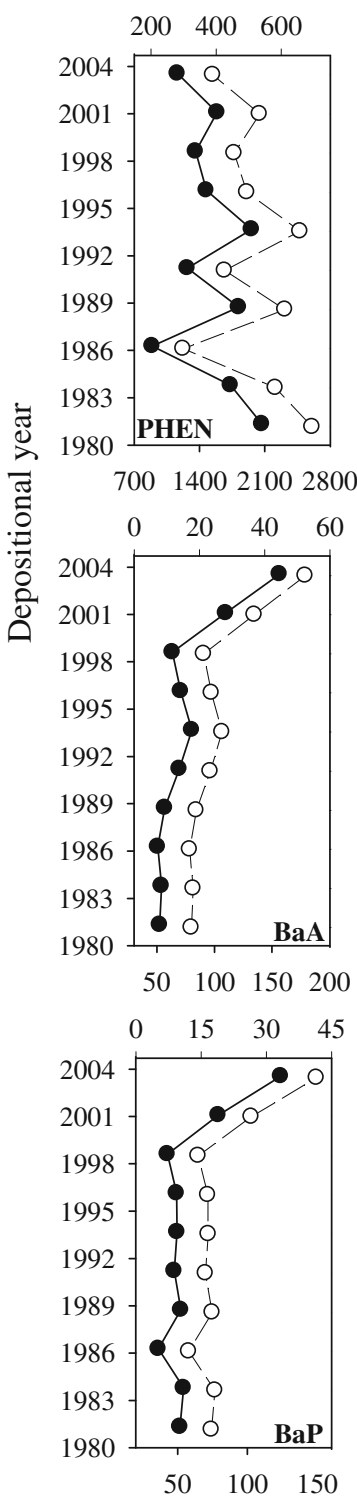

frequently associated with PAH contamination. The assessment results are listed in Supplemental Table 1 and are schematically shown in Fig. 4. Although none of the
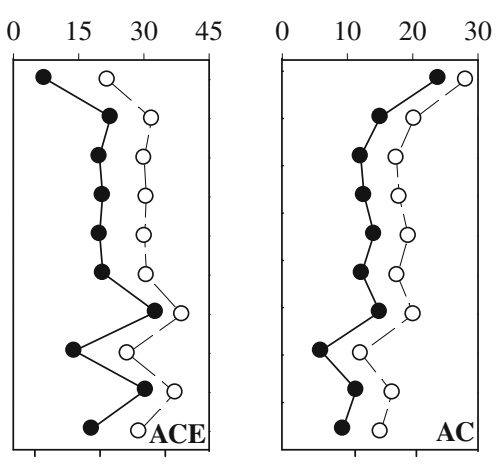

$\begin{array}{llll}25 & 50 & 75 & 100\end{array}$
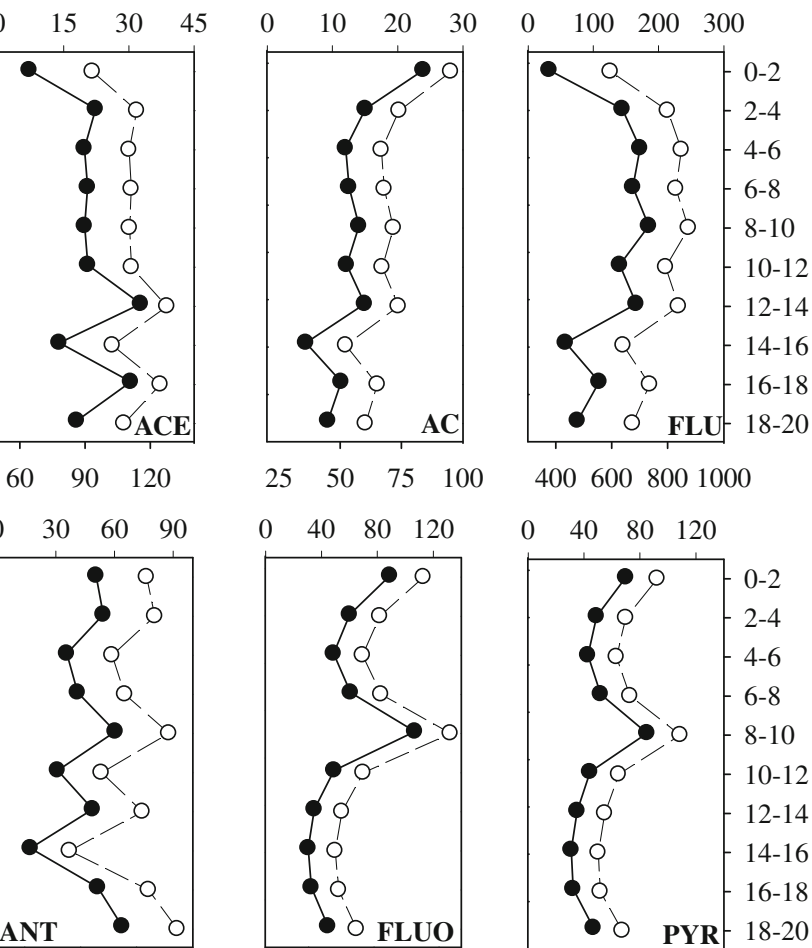

100200300400
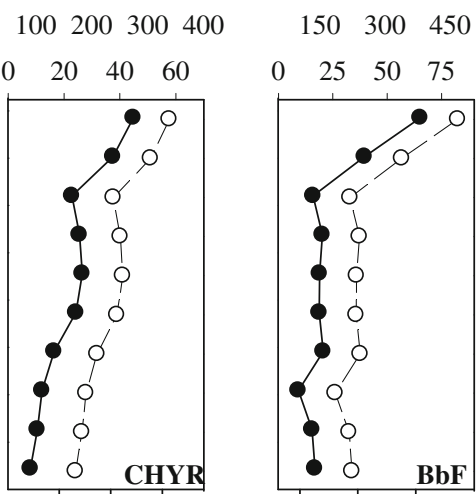

50100150200

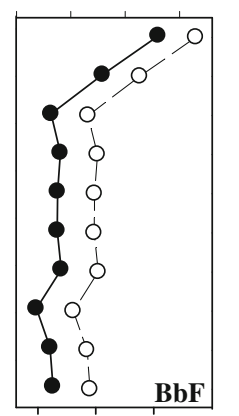

$\begin{array}{llll}80 & 160 & 240 & 320\end{array}$

4006008001000

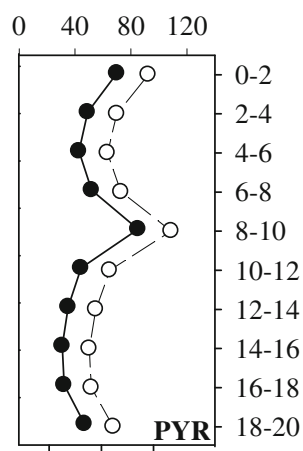

120240360480
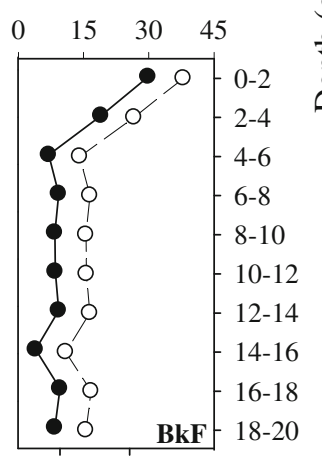

$50 \quad 100 \quad 150$

$\begin{array}{llll}0 & 15 & 30 & 45\end{array}$

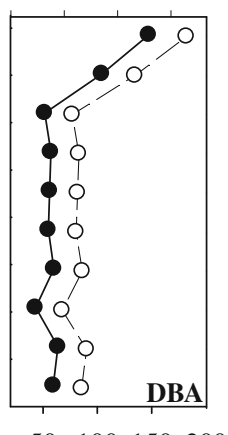

$0 \quad 1530456075$

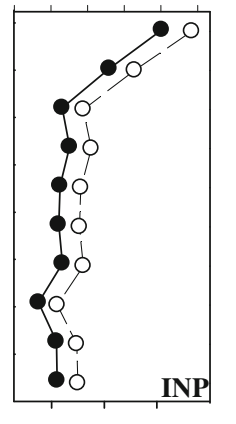

70140210280

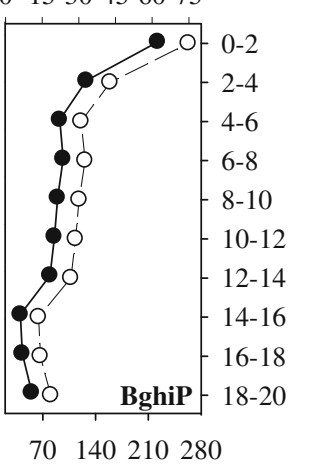

Concentration (ng/g dw.)

HR_ERM values were $>1$, HR_ERL of most low-ring PAHs (including NAP, AC, ACE, FLU, PHEN, and ANT) and DBA were $>1$, suggesting that potential adverse 
Table 1 Characteristic PAH molecular diagnostic ratios

\begin{tabular}{llll}
\hline PAHs & Petrogenic & Pyrogenic & Results from the present work \\
\hline ANT/(ANT + PHEN) & $<0.1$ & $>0.1$ & $0.12 \pm 0.02(0.11-0.16)$ \\
$\mathrm{B} a \mathrm{~A} /(\mathrm{B} a \mathrm{~A}+\mathrm{CHR})$ & $<0.2$ & $>0.35$ & $0.40 \pm 0.03(0.38-0.48)$ \\
FLUO/(FLUO + PYR) & $<0.4$ & $>0.4$ & $0.52 \pm 0.02(0.49-0.55)$ \\
INP/(INP + BghiP) & $<0.2$ & $>0.2$ & $0.53 \pm 0.06(0.47-0.64)$ \\
& Fuel combustion & Grass/coal/wood combustion & \\
FLUO/(FLUO + PYR) & $0.4-0.5$ & $>0.5$ & $0.52 \pm 0.02(0.49-0.55)$ \\
INP/(INP + BghiP) & $0.2-0.5$ & $>0.5$ & $0.53 \pm 0.06(0.47-0.64)$ \\
\hline
\end{tabular}

biologic impact is probable and that further examination is required.

\section{Assessing Sediment Quality Based on Toxic Equivalency Factors}

Another assessment method is based on toxic equivalency factors (TEFs). This assessment method focuses on seven carcinogenic PAHs components (including $\mathrm{B} a \mathrm{~A}, \mathrm{CHR}$, $\mathrm{B} b \mathrm{~F}, \mathrm{~B} k \mathrm{~F}, \mathrm{~B} a \mathrm{P}, \mathrm{DBA}$, and INP). Among the seven carcinogenic PAHs components, $\mathrm{B} a \mathrm{P}$ is the only one having sufficiently toxicologic data for derivation of a carcinogenic factor (Peters et al. 1999). For other carcinogenic PAH components, TEFs were used for quantification (Nadal et al. 2004). According to the USEPA, the TEFs for $\mathrm{B} a \mathrm{P}, \mathrm{B} a \mathrm{~A}, \mathrm{CHR}, \mathrm{B} b \mathrm{~F}, \mathrm{~B} k \mathrm{~F}, \mathrm{INP}$ and $\mathrm{DBA}$ are 1 , $0.1,0.001,0.1,0.01,0.1$, and 1, respectively (Law et al. 2002). The total $\mathrm{B} a \mathrm{P}$ equivalent (TEQ) for seven carcinogenic PAH components can be calculated by the following equation (Eq. 2):

$$
T E Q=\sum C i \times T E F i
$$

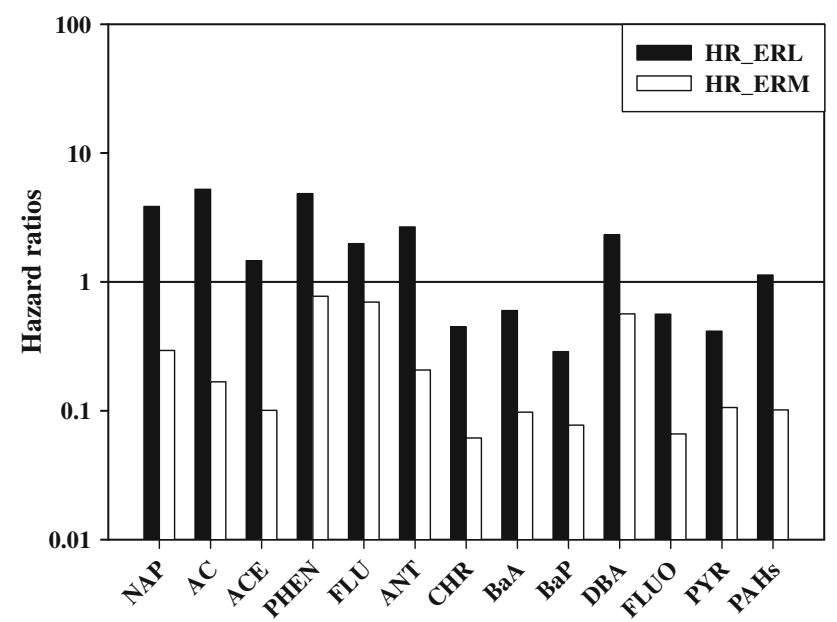

Fig. 4 Risk assessment of PAHs in surface sediment from Lake Hongfeng where $C i$ is the concentration of individual $\mathrm{PAH}$ and $T E F i$ is the corresponding TEF. The TEQ value for the surface sediment from Lake Hongfeng was $334.3 \mathrm{ng} / \mathrm{g}$. Regarding individual carcinogenic PAH components, the contribution to the TEQ of each PAH component decreased in the following order: DBA $(44.0 \%)>\mathrm{B} a \mathrm{P} \quad(37.0 \%)>\mathrm{B} b \mathrm{~F}$ $(7.4 \%)>\operatorname{INP}(6.5 \%)>\mathrm{BaA}(4.7 \%)>\mathrm{CHR}(0.1 \%)$. This indicates that more concern should be paid to DBA and $\mathrm{B} a \mathrm{P}$. A considerably high TEF has been reported for oil-polluted intertidal sediments collected from Yeosu Bay, South Korea (Lee and Yi 1999). The TEQ, which ranged from 94 to $856 \mathrm{ng} / \mathrm{g}$ (average 407) for seven carcinogenic PAH components, has been estimated for surface sediments from Meiliang Bay in the northern part of Taihu Lake in Eastern China (Qiao et al. 2006). The TEQ in this study was lower than those of surface sediments from Meiliang Bay but higher than other reported data, such as the bottom sediments from Guba Pechenga, Barents Sea, in Russia (Savinov et al. 2003).

\section{Conclusion}

PAHs in the sediment core from Lake Hongfeng, Southwest China, and their possible sources and potential toxicologic significance, have been identified. The $\Sigma \mathrm{PAH}_{16}$ concentrations in sediments ranged from 2936.1 to $5282.3 \mathrm{ng} / \mathrm{g}$ and gradually increased from deep to surface sediments. PAHs were dominated by LMW components, especially for PHEN and FLU. However, a significantly increased level of HMW PAHs was found in upper layers of sediment. The temporal trends of individual PAHs suggest that there may have been change in energy use from low- to high-temperature combustion, especially after approximately 2001.

Source identification indicates that PAH input mainly originated from domestic coal combustion and biomass burning. Increasing fuel combustion source has also been found in recent years. Potential adverse biologic impact is probable for DBA and most low-ring PAHs, and more concern should be paid to HMW PAHs, taking into account 
their rapid increasing trends in upper sediments. Because only one core was analyzed, more work is needed to confirm the sources and toxicity of PAHs in Lake Hongfeng.

Acknowledgments The authors are grateful for the financial support from China's national basic research program, "Water Environmental Quality Evolution and Water Quality Criteria in Lakes," (Grant No. 2008CB418200) and the National Natural Science Foundation of China (Grant No. 40973087).

Open Access This article is distributed under the terms of the Creative Commons Attribution Noncommercial License which permits any noncommercial use, distribution, and reproduction in any medium, provided the original author(s) and source are credited.

\section{References}

Brändli RC, Bucheli TD, Kupper T, Mayer J, Stadelmann FX, Tarradellas J (2007) Fate of PCBs, PAHs and their source characteristic ratios during composting and digestion of sourceseparated organic waste in full-scale plants. Environ Pollut 148:520-528

Colombo JC, Cappelletti N, Lasci J, Migoya MC, Speranza E, Skorupka CN (2006) Sources, vertical fluxes, and equivalent toxicity of aromatic hydrocarbons in coastal sediments of the Río de la Plata Estuary, Argentina. Environ Sci Technol 40:734-740

Gu SH, Kralovec AC, Christensen ER, Van Camp RP (2003) Source apportionment of PAHs in dated sediments from the Black River, Ohio. Water Res 37:2149-2161

Guo Z, Lin T, Zhang G, Yang Z, Fang M (2006) High-resolution depositional records of polycyclic aromatic hydrocarbons in the central continental shelf mud of the East China Sea. Environ Sci Technol 40:5304-5311

Guo Z, Lin T, Zhang G, Zheng M, Zhang Z, Hao Y, Fang M (2007) The sedimentary fluxes of polycyclic aromatic hydrocarbons in the Yangtze River Estuary coastal sea for the past century. Sci Total Environ 386:33-41

Harrison RM, Smith DJT, Luhana L (1996) Source apportionment of atmospheric polycyclic aromatic hydrocarbons collected from an urban location in Birmingham. U.K. Environ Sci Technol 30:825-832

He TR, Feng XB, Guo YN, Qiu GL, Li ZG, Liang L, Lu JL (2008) The impact of eutrophication on the biogeochemical cycling of mercury species in a reservoir: a case study from Hongfeng Reservoir, Guizhou, China. Environ Pollut 154:56-67

Kannan K, Johnson-Restrepo B, Yohn SS, Giesy JP, Long DT (2005) Spatial and temporal distribution of polycyclic aromatic hydrocarbons in sediments from Michigan Inland Lakes. Environ Sci Technol 39:4700-4706

Katsoyiannis A, Terzi E, Cai QY (2007) On the use of PAH molecular diagnostic ratios in sewage sludge for the understanding of the PAH sources. Is this use appropriate? Chemosphere 69: 1337-1339

Law RJ, Kelly C, Baker K, Jones J, McIntosh AD, Moffat CF (2002) Toxic equivalency factors for PAH and their applicability in shellfish pollution monitoring studies. J Environ Monit 4: 383-388

Lee B, Yi J (1999) A statistical approach for determining the environmental impact of polynuclear aromatic hydrocarbons in an oil spill-contaminated coastal area. Environ Pollut 105: 391-396
Li W, Wu FC, Liu CQ, Fu PQ, Wang J, Mei Y, Wang LY, Guo JY (2008) Temporal and spatial distributions of dissolved organic carbon and nitrogen in two small lakes on the Southwestern China Plateau. Limnology 9:163-171

Liu GQ, Zhang G, Li XD, Li J, Peng XZ, Qi SH (2005) Sedimentary record of polycyclic aromatic hydrocarbons in a sediment core from the Pearl River Estuary, South China. Mar Pollut Bull 51:912-921

Long ER, MacDonald DD, Smith SL, Calder FD (1995) Incidence of adverse biological effects within ranges of chemical concentrations in marine and estuarine sediments. Environ Manage 19: 81-97

Mai BX, Fu JM, Sheng GY, Kang YH, Lin Z, Zhang G, Min YS, Zeng EY (2002) Chlorinated and polycyclic aromatic hydrocarbons in riverine and estuarine sediments from Pearl River Delta, China. Environ Pollut 117:457-474

Mai BX, Qi SH, Zeng EY, Yang QS, Zhang G, Fu JM, Sheng GY, Peng PA, Wang ZS (2003) Distribution of polycyclic aromatic hydrocarbons in the coastal region off Macao, China: assessment of input sources and transport pathways using compositional analysis. Environ Sci Technol 37:4855-4863

McCready S, Sella DJ, Birch GF, Taylor SE (2000) The distribution of polycyclic aromatic hydrocarbons in surfcial sediments of Sydney Harbour, Australia. Mar Pollut Bull 40:999-1006

Miguel AH, Pereira PAP (1989) Benzo[k]fuoranthene, Benzo[ghi]perylene, and Indeno[1,2,3-cd]pyrene : new tracers of automotive emissions in receptor modeling. Aerosol Sci Technol 10:292-295

Nadal M, Schuhmacher M, Domingo JL (2004) Levels of PAHs in soil and vegetation samples from Tarragona County, Spain. Environ Pollut 132:1-11

Peng X, Wang Z, Yu Y, Tang C, Lu H, Xu S, Chen F, Mai B, Chen S, Li K, Yang C (2008) Temporal trends of hydrocarbons in sediment cores from the Pearl River Estuary and the northern South China Sea. Environ Pollut 156:442-448

Peters CA, Knightes CD, Brown DG (1999) Long-term composition dynamics of PAH-containing NAPLs and implications for risk assessment. Environ Sci Technol 33:4499-4507

Qiao M, Wang C, Huang S, Wang D, Wang Z (2006) Composition, sources, and potential toxicological significance of PAHs in the surface sediments of the Meiliang Bay, Taihu Lake, China. Environ Int 32:28-33

Savinov VM, Savinova TN, Matishov GG, Dahle S, Næs K (2003) Polycyclic aromatic hydrocarbons (PAHs) and organochlorines (Ocs) in bottom sediments of the Guba Pechenga, Barents Sea, Russia. Sci Total Environ 306:39-56

Sicre MA, Marty JC, Saliot A, Aparicio X, Grimalt J, Albaiges J (1987) Aliphatic and aromatic hydrocarbons in different sized aerosols over the Mediterranean Sea: occurrence and origin. Atmos Environ 21:2247-2259

Sverdrup LE, Nielsen T, Krogh PH (2002) Soil ecotoxicity of polycyclic aromatic hydrocarbons in relation to soil sorption, lipophilicity, and water solubility. Environ Sci Technol 36: 2429-2435

Wan GJ, Chen JA, Wu FC, Xu SQ, Bai ZG, Wan EY, Wang CS, Huang RG, Yeager KM, Santschi PH (2005) Coupling between $210 \mathrm{Pbex}$ and organic matter in sediments of a nutrient-enriched lake: an example from Lake Chenghai, China. Chem Geol 224:223-236

Xu J, Yu Y, Wang P, Guo W, Dai S, Sun H (2007) Polycyclic aromatic hydrocarbons in the surface sediments from Yellow River, China. Chemosphere 67:1408-1414

Zeng EY, Venkatesan MI (1999) Dispersion of sediment DDTs in the coastal ocean off southern California. Sci Total Environ 229:195-208 